\title{
Influência do eco-controle no desempenho ambiental e econômico de empresas
}

Ilse Maria Beuren

Universidade Regional de Blumenau

ilse@furb.br

\section{Viviane Theiss}

Universidade Regional de Blumenau

viviane_theiss@hotmail.com

Sodemir Benedito Carli Universidade Regional de Blumenau sodemir@unisep.edu.br

\section{Resumo}

Este estudo objetiva verificar a influência do eco-controle no desempenho ambiental e econômico das empresas. Pesquisa descritiva foi realizada por meio de levantamento e abordagem quantitativa do problema. Um questionário, adaptado do estudo de Henri e Journeault (2010), foi enviado aos diretores das empresas listadas na BM\&FBovespa e com seus dados na Economática ${ }^{\circledR}$, com exceção das entidades financeiras, sendo que as 106 empresas respondentes correspondem a amostra de $30 \%$. Na análise dos dados replicaram-se os procedimentos do estudo de base, distinguindo-se pela aplicação de correlações canônicas com auxílio do software Statgraphics ${ }^{\circledR}$. Os resultados comprovam as hipóteses de que o eco-controle influencia o desempenho econômico de forma direta, como por meio de influências do desempenho ambiental. As variáveis de controle reforçam as evidências em empresas com maior exposição ambiental, visibilidade pública, preocupação ambiental, pressão das partes interessadas e tamanho. Conclui-se que nas empresas pesquisadas o eco-controle influenciou o desempenho econômico e ambiental. Os achados diferem do estudo de Henri e Journeault (2010), que não constataram efeito direto do ecocontrole sobre o desempenho econômico, apenas influência indireta nas variáveis de controle. Estas observações fomentam a literatura com insights sobre a contribuição da contabilidade gerencial ao desenvolvimento sustentável.

Palavras-chave: controle de gestão, eco-controle, desempenho ambiental, desempenho econômico. 


\title{
The influence of eco-control on the environmental and economic performance of companies
}

\begin{abstract}
The goal of this study is to investigate the influence of eco-control on the environmental and economic performance of companies. A descriptive study was conducted through survey and quantitative approach to the problem. A questionnaire, adapted from the study of Henri and Journeault (2010), was sent to directors of companies listed in BM\&FBovespa and data in Economática ${ }^{\circledR}$, with the exception of financial institutions, being the 106 respondent companies the sample of $30 \%$. In the data analyses the procedures of the baseline study were replicated, distinguished by the application of canonical correlations using the software Statgraphics ${ }^{\circledR}$. The results confirm the hypothesis that eco-control influences economic performance directly, and through the influences of environmental performance. The control variables provide further evidence in companies with higher environmental exposure, public visibility, environmental concerns, stakeholder pressure and size. It is concluded that in the companies studied the eco-control influenced the economic and environmental performance. The findings differ from the study of Henri and Journeault (2010), who found no direct effect of eco-control on economic performance, only indirect influence on the control variables. These observations encourage literature with insights on the contribution of management accounting to the sustainable development.
\end{abstract}

Keywords: management control, eco-control, environmental performance, economic performance.

\section{Influencia del eco-control en el desempeño ambiental y económico de las em- presas}

\section{Resumen}

Este estudio tiene como objetivo investigar la influencia del eco-control en el desempeño ambiental y económico de las empresas. El estudio descriptivo se realizó mediante una encuesta y un enfoque cuantitativo del problema. Un cuestionario, adaptado del estudio de Henri y Journeault (2010), fue enviado a los directores de empresas que cotizan en Bovespa y que tienen sus datos en Economática ${ }^{\circledR}$, con la excepción de las instituciones financieras; las 106 empresas que respondieron la encuesta representan una muestra del $30 \%$. En el análisis de los datos, los procedimientos del estudio de referencia se repitieron, mediante el uso del software Statgraphics ${ }^{\circledR}$ que sí distingue la aplicación de las correlaciones canónicas. Los 
resultados confirman la hipótesis de que el eco-control influye en los resultados económicos directamente a través de las influencias de desempeño ambiental. Las variables de control proporcionan una prueba más en las empresas con mayor exposición al medio ambiente, la conciencia pública, la preocupación ambiental, la presión de grupos de interés y el tamaño. Se concluye que, en las empresas estudiadas, el eco-control influyó en el rendimiento económico y medioambiental. Los resultados difieren de los obtenidos por el estudio de Henri y Journeault (2010), el cual no encontró ningún efecto directo del eco-control sobre el desempeño económico, sino sólo una influencia indirecta sobre las variables de control. Estas observaciones fomentan la literatura con ideas sobre la contribución de la contabilidad de gestión para el desarrollo sostenible.

Palabras clave: control de gestión, eco-control, desempeño ambiental, desempeño económico.

\section{Introdução}

O desenvolvimento industrial e novas tecnologias durante muito tempo promoveram prosperidade e trouxeram riqueza às organizações. Entretanto, também causaram degradação ecológica, não necessariamente de forma intencional, como o aquecimento global, destruição da camada de ozônio, desmatamento, desertificação, poluição, declínio da biodiversidade, resíduos tóxicos, entre outros fatores (Shrivastava, 1995).

Apesar de algumas organizações desempenharem papel importante para reverter este quadro, com incentivo e disposição para o controle de problemas ecológicos, elas também podem se beneficiar com outros recursos. Por exemplo, podem aproveitar esse tipo de incentivo, reduzindo custos por meio de eficiência ecológica, desenvolvimento de mercados verdes, melhoria das relações com a comunidade e imagem da instituição (Hart, 1995).

Mais e mais empresas estão alegando que um dos seus principais objetivos é alcançar o desenvolvimento sustentável. Neste contexto, a implementação de instrumentos gerenciais, para ajudar o movimento em prol do desenvolvimento sustentável, estão se tornando cada vez mais importantes para as empresas que desejam assegurar o seu sucesso a longo prazo (Schaltegger e Burrit, 2000). 
A contabilidade de gestão ambiental, também conhecida como Environmental Management Accounting (EMA), pode contribuir para as empresas trabalhar em prol do alcance dos potenciais benefícios, além de enfrentar as suas responsabilidades ambientais perante a sociedade (Burritt e Schaltegger, 2001).

De acordo com Henri e Journeault (2010), como parte da EMA, o eco-controle apresenta uma aplicação de métodos de controle financeiro e estratégico da gestão ambiental. Para os autores, o eco-controle como uma aplicação específica de sistemas de gestão de controle (Management Control Systems, MCS), tem atraído atenção crescente, como um meio de condução de uma estratégia ambiental em toda a empresa. Ajuda também as organizações a medir, controlar e divulgar o seu desempenho ambiental, bem como fornecer informações para tomada de decisões, além de assegurar a consecução dos seus objetivos ambientais e fornecer evidências que comprovam os benefícios de tais ações.

Estudos que mencionam o eco-controle têm predominância para uma análise descritiva ou prescritiva, que contribuem para o seu desenvolvimento nesta área, como descrevem Eckel, Fisher e Russell (1992), Burritt e Schaltegger (2001), e Figge et al. (2002). Entretanto, muitas vezes estes estudos estão baseados em dados limitados de estudos de caso, por sofrerem da falta de evidência empírica, como destaca Burritt (2004).

De acordo com Henri e Journeault (2010), estudos recentes tentam suprir lacunas, ao explorar empiricamente alguns aspectos do eco-controle. Como é o caso de Judge e Douglas (1998), que têm testado a influência do eco-controle sobre o desempenho ambiental e econômico de empresas. Os resultados do estudo evidenciam relações positivas entre o planejamento estratégico ambiental e o desempenho ambiental e econômico das empresas.

Depreende-se do exposto que ainda há espaço para novas pesquisas empíricas. Neste sentido elaborou-se a seguinte questão problema deste estudo: Qual a influência do eco-controle no desempenho ambiental e econômico das empresas listadas na BM\&FBovespa? Assim, o objetivo deste estudo é verificar a influência do eco-controle no desempenho ambiental e econômico de empresas.

O estudo justifica-se pela necessidade de obter maiores conhecimentos do ecocontrole. A pesquisa pode ser entendida como uma maneira de verificar a aplicação de uma ação específica de sistema de controle de gestão, particularmente pelo seu 
impacto nas organizações. Além disso, contribui para uma nova abordagem da contabilidade gerencial e a conscientização do controle ambiental pelas empresas.

Na pesquisa realiza-se um levantamento de dados por meio de um questionário adaptado do estudo de Henri e Journeault (2010), para as empresas listadas no ano de 2011 na BM\&FBovespa e com seus dados disponíveis na Economática ${ }^{\circledR}$. Os dados coletados buscam investigar o efeito direto do eco-controle sobre desempenho econômico, bem como o efeito indireto por meio do desempenho ambiental.

O estudo está organizado em cinco seções, iniciando com esta introdução. Em seguida, faz uma incursão teórica no eco-controle, desempenho ambiental e desempenho econômico. Também discorre sobre o estudo de Henri e Journeault, publicado em 2010 no periódico Accounting, Organization and Society, no qual está baseada esta pesquisa. Após são expostos os procedimentos metodológicos da pesquisa. Na sequência, faz a descrição e análise dos resultados da pesquisa e apresenta as conclusões do estudo.

\section{Referencial teórico}

Nesta seção faz-se uma incursão teórica em aspectos relativos ao eco-controle, desempenho ambiental e desempenho econômico. Também se discorre sobre procedimentos adotados e a contextualização do estudo realizado por Henri e Journeault (2010), que fundamenta esta pesquisa.

\section{Eco-controle}

Na gestão financeira das organizações, as informações contábeis são usadas para o controle e o processo de tomada de decisões. Analogamente, o eco-controle exerce estas funções no processo de gestão ambiental das empresas, ao qual fornece um sistema de apoio à decisão para a gestão (Schaltegger e Burrit, 2000).

Henri e Journeault (2010) consideram o eco-controle como um processo pelo qual os gestores asseguram que os recursos econômicos e ecológicos sejam obtidos e aproveitados de forma eficaz e eficiente na realização dos objetivos da organização, desenvolvidos para ajudar a organização a adaptar-se ao ambiente em que está inserida e alcançar os resultados desejados pelos stakeholders. 
Para Alberton e Costa Jr (2007), além das pressões regulatórias e sociais, ocorre a busca por uma melhor reputação, pois os stakeholders estão, a cada dia, mais atentos às relações entre as entidades e o meio ambiente, que exigem um elevado preço das empresas em casos de agressões ambientais, mesmo que sejam acidentais ou involuntárias. Os autores informam que as práticas ambientais corporativas tendem a se tornarem menos uma questão ambiental e mais uma questão de estratégia competitiva, de relações humanas, eficiência operacional, marketing, finanças e desenvolvimento de produtos.

Neste contexto, o eco-controle é utilizado para quantificar as ações ambientais e integrar as preocupações ambientais nas rotinas da organização, ou seja, melhorar o alinhamento entre estratégia de negócios e estratégias ambientais (Baines e Langfield-Smith, 2003). O eco-controle permite a realização de inspeções em relação às práticas ambientais.

De acordo com Schaltegger e Burrit (2000), no princípio o eco-controle foi projetado para a indústria de transformação. Em seguida foi adaptado e aplicado na indústria de serviços e na gestão da fauna e da flora. No entanto, há possibilidade de sua aplicação em qualquer entidade, de todos os tamanhos, que deseja realizar tentativas de melhorar a gestão ambiental.

Sua gestão é baseada no processo básico de controle financeiro, que prevê uma abordagem para as questões ambientais e propõe um procedimento de gestão por etapas para apoio à decisão, controle, implementação e comunicação. $\mathrm{O}$ conceito é desenvolvido especificamente para ligar tática ambiental, metas financeiras e estratégicas da gestão de topo (Muller e Wittke, 1997).

Segundo Schaltegger e Burrit (2000), como o controle financeiro e o controle estratégico são definidos de maneiras diferentes de empresa para empresa, da mesma forma, o eco-controle apresenta diversas versões. Porém, os autores destacam três abordagens principais: I) Financeira, em que o dinheiro é usado como unidade de medida; II) Contábil, em que as unidades de medida utilizadas são expressas em termos físicos; e III) Modelo integrado das duas abordagens mencionadas. Ressaltam ainda que em muitas empresas de pequeno, médio e grande porte, que apresentam o eco-controle como prática de gestão, observam-se melhorias na eficiência e em seu desempenho ambiental. 


\section{Desempenho ambiental}

Na literatura contábil, o desempenho ambiental tem sido examinado principalmente em termos dos impactos ambientais gerados na condução dos negócios, como resíduos perigosos reciclados (Al-Tuwaijri et al., 2004). Além disso, são citados liberais tóxicos, poluição, desperdício de água e não-conformidade com os estatutos ambientais (Mobus, 2005).

O conceito de desempenho, de acordo com Ilinitch et al. (1998), não se limita ao aspecto financeiro, mas integra também outros elementos como, satisfação do cliente, produtividade, qualidade, inovação e o próprio desempenho ambiental. Muller e Wittke (1997) explicam que o "desempenho ambiental está ligado principalmente aos impactos ambientais causados por riscos (acidentes) ou por intervenções contínuas no ambiente natural”.

Estudos sobre gestão ambiental, como os de Sharma e Vredenburg (1998), abordam que o desempenho ambiental se refere ao processo e melhorias de produtos resultantes da integração de considerações ambientais nas decisões operacionais da empresa, assim como, uma consideração dos grupos de interesse relacionados a organização. Eckel et al. (1992) reportam que "o sistema de informação ambiental deverá ser relacionado com as políticas ambientais da organização e seus objetivos, e também com a regulamentação ambiental e percepções da sociedade sobre como as atividades de uma organização afetam o meio ambiente".

Neste contexto, Henri e Journeault (2010) definem "desempenho ambiental como a capacidade da organização estabelecer relações harmoniosas entre as várias partes interessadas com as questões ambientais". As partes interessadas caracterizamse como valores, tanto internos como externos da organização. Bebbington et al. (1994) descrevem que os valores internos enfatizam o gerencialismo, que se refere a uma visão de negócios em que as conseqüências econômicas das ações ambientais são destacadas na avaliação do desempenho ambiental. Para os valores externos referem-se a uma visão orientada para a sustentabilidade em que a proteção e melhoria do ambiente são produzidas com maior ênfase.

Para integrar as dimensões de desempenho ambiental, Ilinitch et al. (1998) separam a matriz de desempenho ambiental em dois eixos: o eixo vertical se refere ao processo e resultados; e o eixo horizontal reflete a dimensão interno-externo. De 
acordo com os autores, a junção dos eixos fornece uma estrutura para organizar as diversas opiniões de desempenho ambiental em quatro aspectos: I) Impacto ambiental e imagem corporativa, que analisa a reputação da empresa e em que medida atende ou excede os padrões exigidos por leis e regulamentos relativos às emissões e descargas; II) O produto das relações das partes interessadas, que se referem à interação entre a organização e seus vários componentes externos, incluindo seus acionistas, a comunidade local, governo, clientes, fornecedores e indústria; III) Impacto financeiro, caracteriza as consequências monetárias associadas às práticas ambientais, tais como redução nos custos de material, redução de processos/custos de produção e redução dos custos de conformidade regulamentar; IV) Melhorias de processo e produto, referem-se à integração das questões ambientais nas operações, que resulta em vantagem competitiva para a organização, tais como a melhoria da qualidade, aumento da inovação, produtividade melhorada. Os autores lembram ainda, que todos os aspectos citados são necessários, mas não suficientes para verificar um desempenho ambiental geral.

É esperado do eco-controle contribuir à promoção do desempenho ambiental em quatro perspectivas: por meio do feedback, de informações para tomada de decisão, atenção da organização perante seu desempenho ambiental e dados para relatórios externos. O feedback, de acordo com Chenhall (2005), ocorre como uma forma de monitorar o cumprimento das políticas ambientais, objetivos e regulamentos da organização, para que as metas ambientais definidas sejam cumpridas e possam proporcionar reflexões apropriadas para propriedades ambientais, consequentemente, a promoção para o desempenho ambiental.

A contribuição por meio de informações para tomada de decisão, conforme descreve Chenhall (2005), ocorre porque, os gestores necessitam de uma quantidade de informações razoáveis de seu eco-controle, para apoiar as decisões relacionadas à redução de custos, processos e eficiência de produção, melhoria do produto, entre outros. A terceira perspectiva, atenção da organização perante seu desempenho ambiental, é como uma forma para a melhoria contínua da organização (Eckel et al., 1992; Burritt, 2004).

Sobre a quarta perspectiva, Dixon et al. (2005) mencionam que os relatórios ambientais são um meio para a organização responder às pressões das partes interessadas, além de revelarem os impactos financeiros e não financeiros de questões ambientais. Essas práticas contribuem para: criação de uma reputação de boa imagem corporativa; benefícios de marketing; percepções do público relativas às 
operações da organização; manter legitimidade social. Para Patten (2005), as organizações utilizam essas informações para demonstrar que estão operando dentro das normas e valores da sociedade, a fim de reduzir a probabilidade de ações de política pública contra a organização.

\section{Desempenho econômico}

Estudos como os de Baines e Langfield-Smith (2003) e Said et al. (2003) defendem a associação entre eco-controle e desempenho econômico de empresas. Para Said et al. (2003), as empresas estão cada vez mais interessadas "em sistemas de medição de desempenho para controlar novas métricas não financeiras, tais como a satisfação do cliente, funcionário, qualidade, participação de mercado, produtividade e inovação". Os autores fazem a relação contextual com fatores ambientais.

Baines and Langfield-Smith (2003) mencionam que o eco-controle poderá apoiar o desempenho econômico, como um meio de fornecimento de informações incrementais, tais como, dados sobre incorporação de ações gerenciais e questões ambientais que não são totalmente capturados em resultados financeiros. Além disso, contribuir para a manutenção e desenvolvimento de capacidades organizacionais que conduzam à realização de vantagens competitivas sustentáveis e um desempenho superior ao planejado.

Da mesma forma Barata et al. (2007) informam que, diversos instrumentos de desempenho ambiental proporcionam uma série de vantagens econômicas, como redução de custos, aumento de competitividade, abertura de novos mercados, entre outros. Depreende-se por esses relatos que há uma relação entre aspectos do desempenho ambiental com o desempenho econômico.

Para o desenvolvimento sustentável o eco-controle apresenta três dimensões distintas, de acordo com Schaltegger e Burritt (2000): econômicas, ambientais e sociais. Preocupado principalmente com as relações de influência e poder, o controle ambiental está crescendo como uma ferramenta de gerenciamento disponível para todas as empresas (Schaltegger e Burrit, 2000). É possível supor que por meio do eco-controle haverá maior desempenho econômico entre as entidades. 
O estudo de Henri e Journeault (2010)

O estudo de Henri e Journeault, publicado em 2010 no periódico Accounting, Organization and Society, buscou investigar até que ponto o eco-controle influencia o desempenho ambiental e econômico. Aplicado a uma amostra de 1.500 empresas canadenses da base de dados Scott Manufacturing, e com a intenção de selecionar somente as grandes, com sistema de gestão desenvolvido, os autores separaram as empresas com 100 funcionários ou mais e vendas com 20 milhões de dólares ou mais. A amostra, após esta primeira triagem, resultou em 1.447 empresas.

Em seguida, enviaram o questionário para um membro da gestão de topo de cada empresa e obtiveram 303 questionários válidos, que representou 20,9\% de respostas. Entretanto, antes do envio do questionário, os autores efetuaram um pré-teste com vários acadêmicos e gestores, para efetuar os ajustes necessários no instrumento de pesquisa.

Na figura 1 apresenta-se o desenho do estudo estabelecido por Henri e Journeault (2010), que reflete as relações entre eco-controle, desempenho ambiental e desempenho econômico.

Figura 1

Visão geral do modelo conceitual

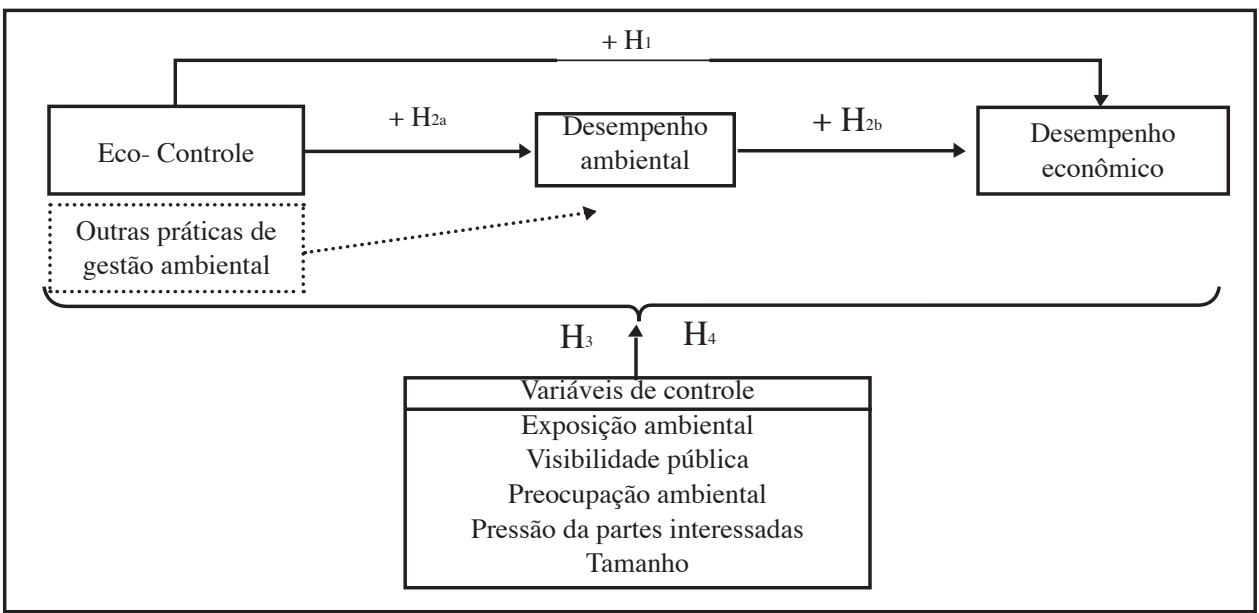

Fonte: Adaptado de Henri e Journeault (2010). 
Conforme exposto na figura 1, o eco-controle deve apresentar influência positiva e direta com o desempenho econômico (hipótese $\mathrm{H}_{1}$ ). $\mathrm{O}$ eco-controle deve contribuir de forma positiva e indiretamente para o desempenho econômico por meio do desempenho ambiental (hipótese $\mathrm{H}_{2}$ ), e entre o sistema de controle de gestão (MCS) e desempenho econômico, influenciado por variáveis de controle (Chenhall, 2005).

Henri e Journeault (2010) descrevem que os efeitos diretos e indiretos do eco-controle sobre o desempenho econômico são maiores para as empresas com: I) exposição ambiental, II) visibilidade pública, III) preocupação ambiental, IV) pressão das partes interessadas e V) tamanho (hipóteses $\mathrm{H}_{3} \mathrm{e} \mathrm{H}_{4}$ ).

Para averiguar a confiabilidade das respostas da pesquisa, Henri e Journeault (2010) aplicaram o teste de Alpha de Cronbach. Além disso, foi estabelecida a análise fatorial confirmatória de primeira e segunda ordem. De acordo com Fávero et al. (2009), "a análise fatorial, ou análise do fator comum, é uma técnica multivariada de interdependência que busca sintetizar as relações observadas entre um conjunto de variáveis inter-relacionadas, buscando identificar fatores comuns".

Após o procedimento descrito, a análise dos dados foi realizada em três etapas, iniciando com a modelagem de equações estruturais (SEM), em que efetuaram regressões lineares simultâneas com as variáveis (eco-controle, desempenho ambiental, desempenho econômico e outras práticas de gestão ambiental). Em um segundo momento, uma nova avaliação, com as mesmas variáveis, mas desta vez utilizando as variáveis de controle. E por fim, para avaliar a significância dos efeitos indiretos do eco controle sobre o desempenho econômico via desempenho ambiental (hipóteses $\mathrm{H}_{3}$ e $\mathrm{H}_{4}$ ), aplicaram o teste de Sobel, em uma versão chamada Aroian do teste de Sobel.

Os resultados apontaram que o eco-controle não tem efeito direto sobre o desempenho econômico. Entretanto, o eco-controle apresenta uma influência indireta sobre o desempenho econômico no contexto de: I) maior exposição ambiental, II) maior visibilidade pública, III) maior preocupação ambiental, IV) pressão das partes interessadas e V) tamanho.

\section{Método de pesquisa}

O desenvolvimento do estudo realizou-se por meio de pesquisa descritiva, com abordagem quantitativa e um levantamento ou survey. Richardson (1989) aduz 
que a pesquisa descritiva constitui-se de estudo que "representa um nível de análise que permite identificar as características dos fenômenos, possibilitando, também, a ordenação e classificação destes". Sobre a abordagem quantitativa, o autor caracteriza-a pelo emprego da quantificação, tanto de modalidades de coleta das informações, como no tratamento dessas, por meio de técnicas estatísticas, que tem a intenção de garantir a precisão dos resultados.

No que concerne à pesquisa de levantamento, Kerlinger (1980) explica que "nos levantamentos, pequenas e grandes populações são estudadas através de amostras para descobrir a incidência relativa, a distribuição e inter-relações de variáveis psicológicas e sociológicas". O autor destaca também que o levantamento tem sido utilizado, mas não exclusivamente, para desvendar como existe e o que existe no ambiente social de um grupo.

\section{População e amostra}

A população da pesquisa foi definida de forma intencional, por conveniência. Compreende todas as empresas listadas na BM\&FBovespa no ano de 2011 e que têm seus dados disponíveis na Economática ${ }^{\circledR}$. Desta listagem foram excluídas as empresas financeiras, por apresentarem informações contábeis diversas das demais. Também foram excluídas as empresas que não tinham seu endereço eletrônico disponível em ambas as listagens. Desta forma, a amostra inicial compreendeu 357 empresas.

Para estas empresas foi enviado o instrumento de pesquisa de forma eletrônica em setembro de 2011. Três semanas após, enviou-se um lembrete via telefone para que cada empresa fosse motivada e orientada para responder a pesquisa. Após 45 dias, encerrou-se o recebimento dos questionários, e foi obtido um montante de 122 respostas.

Uma triagem dos questionários foi realizada, em que se retiraram as empresas que não responderam todas as questões solicitadas. Também se excluíram as empresas que registraram um número inferior a 100 empregados. Na quadro 1 apresenta-se a quantidade de empresas por setor e a composição da amostra deste estudo. 


\section{Quadro 1}

\section{Amostra das empresas por setor}

\begin{tabular}{l|c|c|c|c|c|c|c}
\hline Setor & $\begin{array}{c}\text { População } \\
\text { p/setor } \\
\text { (Quant.) }\end{array}$ & $\begin{array}{c}\text { Amostra } \\
\text { necessária } \\
\text { (Quant.) }\end{array}$ & $\begin{array}{c}\text { Erro de } \\
\text { precisão }\end{array}$ & $\begin{array}{c}\text { Intervalo de } \\
\text { confiança }\end{array}$ & $\begin{array}{c}\text { Amostra } \\
\text { inicial }\end{array}$ & $\begin{array}{c}\text { Tamanho da } \\
\text { amostra }\end{array}$ & $\begin{array}{c}\text { Amostra } \\
\text { Obtida } \\
\text { (Quant.) }\end{array}$ \\
\hline Bens industriais & 35 & 11 & 0.10 & 0.95 & 100 & 10 & 11 \\
\hline $\begin{array}{l}\text { Construção e } \\
\text { transporte }\end{array}$ & 69 & 21 & 0.10 & 0.95 & 100 & 12 & 25 \\
\hline $\begin{array}{l}\text { Consumo cíclico } \\
\text { Consumo não } \\
\text { cíclico }\end{array}$ & 63 & 19 & 0.10 & 0.95 & 100 & 12 & 16 \\
\hline Materiais Básicos & 46 & 13 & 0.10 & 0.95 & 100 & 9 & 8 \\
\hline $\begin{array}{l}\text { Petróleo, gás e } \\
\text { biocombustíveis }\end{array}$ & 7 & 2 & 0.10 & 0.95 & 100 & 9 & 17 \\
\hline $\begin{array}{l}\text { Tecnologia da } \\
\text { informação }\end{array}$ & 7 & 2 & 0.10 & 0.95 & 100 & 2 & 2 \\
\hline Telecomunicações & 16 & 5 & 0.10 & 0.95 & 100 & 4 & 1 \\
\hline Utilidade Publica & 72 & 22 & 0.10 & 0.95 & 100 & 13 & 19 \\
\hline Média geral & $\mathbf{3 5 7}$ & $\mathbf{1 0 7}$ & - & - & - & 72 & $\mathbf{1 0 6}$ \\
\hline
\end{tabular}

Fonte: Dados da pesquisa.

No quadro 1 observa-se a população da pesquisa por setor da BM\&FBovespa, a amostra necessária de no mínimo $30 \%$ da população, o erro de precisão de $10 \%$, o intervalo de confiança de $95 \%$ e o tamanho da amostra. Exibe também a amostra obtida, que corresponde aos 106 questionários viáveis para a análise dos dados.

\section{Constructo e instrumento da pesquisa}

No quadro 2 apresentam-se as variáveis e subvariáveis para medir o eco-controle, o desempenho ambiental, o desempenho econômico e outras práticas de gestão ambiental. Ao constructo adicionaram-se as respectivas perguntas do instrumento de pesquisa, elaboradas com base no estudo de Henri e Journeault (2010), consubstanciadas nas pesquisas dos autores registrados em frente a cada variável/subvariável. 


\section{Quadro 2 \\ Constructo e perguntas do questionário adaptado de Henri e Journeault (2010)}

\begin{tabular}{|c|c|c|c|}
\hline Autores & Variáveis & Subvariáveis & Questões do instrumento de pesquisa \\
\hline \multirow{4}{*}{$\begin{array}{c}\text { Bennett e James } \\
\text { (1998) }\end{array}$} & \multirow{10}{*}{ Eco-Controle } & \multirow{4}{*}{$\begin{array}{c}\text { Uso de medidas de } \\
\text { desempenho }\end{array}$} & $\begin{array}{l}\text { Monitora a conformidade interna com as políticas } \\
\text { ambientais e regulamentos }\end{array}$ \\
\hline & & & Fornece dados para tomada de decisão interna \\
\hline & & & Motiva a melhoria contínua \\
\hline & & & Fornece dados para relatórios externos \\
\hline \multirow{3}{*}{$\begin{array}{l}\text { Henri e Journeault } \\
\text { (2010) }\end{array}$} & & \multirow{3}{*}{$\begin{array}{l}\text { Detalhamento do } \\
\text { orçamento }\end{array}$} & Gastos ambientais \\
\hline & & & Investimento ambiental \\
\hline & & & $\begin{array}{l}\text { Renda a partir da sucata de material ou resíduos } \\
\text { reciclados }\end{array}$ \\
\hline \multirow{3}{*}{ Sharma (2000) } & & \multirow{3}{*}{$\begin{array}{l}\text { Extensão de } \\
\text { incentivos }\end{array}$} & $\begin{array}{l}\text { Indicadores ambientais são importantes em sistemas de } \\
\text { recompensa }\end{array}$ \\
\hline & & & $\begin{array}{l}\text { Objetivos de desempenho ambiental são incluídos nos } \\
\text { sistemas de planejamento }\end{array}$ \\
\hline & & & $\begin{array}{l}\text { Indicadores de desempenho ambiental são ponderados } \\
\text { com indicadores de desempenho econômico }\end{array}$ \\
\hline \multirow{15}{*}{$\begin{array}{c}\text { Sharma e } \\
\text { Vredenburg (1998) }\end{array}$} & \multirow{15}{*}{$\begin{array}{l}\text { Desempenho } \\
\text { ambiental }\end{array}$} & \multirow{15}{*}{$\begin{array}{c}\text { Benefícios das } \\
\text { práticas ambientais }\end{array}$} & Redução de custos de material \\
\hline & & & Redução no processo/custos de produção \\
\hline & & & Redução dos custos de conformidade legal \\
\hline & & & Aumento da eficiência do processo/produção \\
\hline & & & Aumento na produtividade \\
\hline & & & $\begin{array}{l}\text { Aumento do conhecimento sobre formas eficazes de } \\
\text { gestão de operações }\end{array}$ \\
\hline & & & Inovações de melhoria em processos \\
\hline & & & Aumento da qualidade do produto \\
\hline & & & Inovações de melhoria em produtos \\
\hline & & & $\begin{array}{l}\text { Aumento do nível de aprendizagem organizacional entre } \\
\text { os funcionários }\end{array}$ \\
\hline & & & $\begin{array}{l}\text { Melhor relacionamento com as partes interessadas, } \\
\text { tais como as comunidades locais, reguladores e grupos } \\
\text { ambientalistas }\end{array}$ \\
\hline & & & Moral dos funcionários melhorou \\
\hline & & & Reputação geral ou goodwill da empresa melhorou \\
\hline & & & Filtros e controles sobre as emissões e descargas \\
\hline & & & Reciclagem de resíduos \\
\hline \multirow{3}{*}{$\begin{array}{l}\text { Henri e Journeault } \\
\text { (2010) }\end{array}$} & \multirow{3}{*}{$\begin{array}{l}\text { Desempenho } \\
\text { econômico }\end{array}$} & \multirow{3}{*}{$\begin{array}{c}\text { Desempenho } \\
\text { econômico dos } \\
\text { últimos } 12 \text { meses } \\
\end{array}$} & Retorno sobre o investimento (ROI) \\
\hline & & & Lucros operacionais \\
\hline & & & Fluxo de caixa das operações \\
\hline \multirow{12}{*}{$\begin{array}{l}\text { Aragon-Correa } \\
\text { (1998) }\end{array}$} & \multirow{12}{*}{$\begin{array}{c}\text { Outras } \\
\text { práticas } \\
\text { de gestão } \\
\text { ambiental }\end{array}$} & \multirow{12}{*}{$\begin{array}{c}\text { Importância } \\
\text { dos recursos } \\
\text { naturais } \\
\text { na gestão } \\
\text { ambiental }\end{array}$} & Uso de argumentos ambientais naturais em marketing \\
\hline & & & Aspetos ambientais naturais no trabalho administrativo \\
\hline & & & Auditorias periódicas de ambientes naturais \\
\hline & & & Manual de compra com as diretrizes ecológicas \\
\hline & & & Seminários sobre ambientes naturais para executivos \\
\hline & & & $\begin{array}{l}\text { Formação sobre ambientes naturais para os } \\
\text { funcionários da empresa }\end{array}$ \\
\hline & & & $\begin{array}{l}\text { Programa de qualidade total com os aspectos } \\
\text { ambientais naturais }\end{array}$ \\
\hline & & & Uso de seguro a danos causados pela poluição \\
\hline & & & Manual de gestão ambiental natural para uso interno \\
\hline & & & Análise ambiental natural do ciclo de vida do produto \\
\hline & & & $\begin{array}{l}\text { Participação em programas ambientais naturais } \\
\text { subsidiados pelo governo }\end{array}$ \\
\hline & & & Patrocínio de eventos ambientais naturais \\
\hline
\end{tabular}


Observa-se no quadro 2 que o eco-controle foi investigado com base em três possíveis práticas. A primeira, o uso de medidas de desempenho, proposto por Bennett e James (1998), ao analisar, a conformidade interna com as políticas ambientais, se o eco-controle fornece dados para a tomada de decisão, motiva a melhoria contínua da entidade e fornece dados para relatórios externos. A segunda medida, caracterizada pelo orçamento, estabelecida no estudo de Henri e Journeault (2010), verifica se as empresas definem as suas metas levando em conta seus gastos com despesas ambientais, as receitas a partir da sucata de materiais reciclados e investimentos ambientais. A terceira medida verifica os incentivos presentes na prática ambiental, conforme aborda Sharma (2000), representados pelos fatores que levam as empresas a exercerem suas práticas ambientais.

Procedimento idêntico foi adotado para as demais variáveis. No quadro 3 apresentam-se as variáveis de controle com as subvariáveis e os autores que as utilizaram em suas pesquisas. Os dados das variáveis preocupação ambiental e pressões das partes interessadas foram coletados por meio de questionário, do mesmo modo como as variáveis de pesquisa. Já para as demais variáveis de controle, os dados foram extraídos da Economática®.

Ressalta-se que o questionário foi adaptado da pesquisa de Henri e Journeault (2010) e de autores referenciados neste instrumento de pesquisa, que abordam sobre medidas de desempenho (Bennett e James, 1998), indicadores de desempenho ambiental (Sharma e Vredenburg, 1998), interesse ambiental (Judge e Douglas, 1998), aplicação de outras práticas de gestão ambiental (Aragão-Correia, 1998), utilização de incentivos (Sharma, 2000) e informações das partes interessadas (Buysse e Verbeke, 2003). 


\section{Quadro 3 \\ Constructo das variáveis de controle e perguntas adaptadas de Henri e Journeault (2010)}

\begin{tabular}{|c|c|c|c|}
\hline Autores & Variáveis & Subvariáveis & $\begin{array}{c}\text { Questões do instrumento de pesquisa/Medidas } \\
\text { específicas }\end{array}$ \\
\hline \multirow{2}{*}{$\begin{array}{c}\text { Al-Tuwaijri, } \\
\text { Christensen e } \\
\text { Hughes (2004) }\end{array}$} & \multirow{2}{*}{$\begin{array}{l}\text { Exposição } \\
\text { ambiental }\end{array}$} & \multirow{2}{*}{\begin{tabular}{|c|} 
Listada no \\
Índice de \\
Sustentabilidade \\
Epresarial \\
\end{tabular}} & $\begin{array}{l}\text { Variável dummy, com pontuação } 1 \text { para as empresas } \\
\text { listadas no ISE, e } 0 \text { para as não listadas }\end{array}$ \\
\hline & & & Dados extraídos da Economática ${ }^{\circledR}$ \\
\hline \multirow{2}{*}{$\begin{array}{c}\text { Al-Tuwaijri, } \\
\text { Christensen e } \\
\text { Hughes (2004) }\end{array}$} & \multirow{2}{*}{$\begin{array}{l}\text { Propriedade } \\
\text { (visibilidade } \\
\text { pública) }\end{array}$} & \multirow{2}{*}{$\begin{array}{c}\text { Propriedade } \\
\text { pública do capital }\end{array}$} & $\begin{array}{l}\text { Variável dummy, com pontuação } 1 \text { para as empresas de } \\
\text { propriedade pública, e } 0 \text { para as sem essa propriedade }\end{array}$ \\
\hline & & & Dados extraídos da Economática® \\
\hline \multirow{6}{*}{$\begin{array}{c}\text { Judge e } \\
\text { Douglas (1998) }\end{array}$} & \multirow{6}{*}{$\begin{array}{c}\text { Preocupação } \\
\text { ambiental. }\end{array}$} & $\begin{array}{l}\text { Cobertura } \\
\text { funcional }\end{array}$ & \begin{tabular}{|l|} 
Produção/operação \\
Marketing / compras / vendas \\
Contabilidade / finanças / jurídico \\
\end{tabular} \\
\hline & & \multirow{2}{*}{$\begin{array}{l}\text { Integração } \\
\text { das questões } \\
\text { ambientais }\end{array}$} & $\begin{array}{l}\text { Dentro do processo de planejamento } \\
\text { Equipe de gestão de topo toma as decisões de forma } \\
\text { pró-ativa }\end{array}$ \\
\hline & & & Participação do pessoal ambiental no planejamento \\
\hline & & \multirow{2}{*}{$\begin{array}{l}\text { Desempenho } \\
\text { financeiro }\end{array}$} & Retorno sobre o investimento \\
\hline & & & \begin{tabular}{|l|} 
Crescimento das vendas e dos lucros \\
Mudança da fatia de mercado
\end{tabular} \\
\hline & & $\begin{array}{l}\text { Desempenho } \\
\text { ambiental }\end{array}$ & $\begin{array}{l}\text { Conformidade com os regulamentos } \\
\text { Capacidade de limitar o impacto ambiental além do } \\
\text { exigido } \\
\text { Educação dos trabalhadores e do público }\end{array}$ \\
\hline \multirow{8}{*}{$\begin{array}{c}\text { Buysse e } \\
\text { Verbeke (2003) }\end{array}$} & \multirow{8}{*}{$\begin{array}{c}\text { Pressões } \\
\text { das partes } \\
\text { interessadas. }\end{array}$} & \multirow{2}{*}{$\begin{array}{c}\text { Partes } \\
\text { interessadas } \\
\text { externas }\end{array}$} & Clientes \\
\hline & & & Fornecedores \\
\hline & & \multirow{2}{*}{$\begin{array}{l}\text { Partes } \\
\text { interessadas } \\
\text { secundárias. }\end{array}$} & \begin{tabular}{|l|} 
Concorrentes \\
ONGs ambientais \\
\end{tabular} \\
\hline & & & Imprensa \\
\hline & & \multirow{3}{*}{$\begin{array}{l}\text { Partes } \\
\text { interessadas } \\
\text { internas }\end{array}$} & Funcionários \\
\hline & & & Acionistas \\
\hline & & & Instituições financeiras \\
\hline & & $\begin{array}{l}\text { Interessados } \\
\text { reguladores }\end{array}$ & $\begin{array}{l}\text { Interessados, reguladores nacionais (e regionais), } \\
\text { governos }\end{array}$ \\
\hline \multirow{2}{*}{$\begin{array}{l}\text { Henri e } \\
\text { Journeault } \\
(2010)\end{array}$} & \multirow{2}{*}{ Tamanho } & \multirow{2}{*}{$\begin{array}{l}\text { Número de } \\
\text { empregados }\end{array}$} & Logaritmo neperiano do número de empregados \\
\hline & & & Dados extraídos da Economática® \\
\hline
\end{tabular}

Fonte: Elaboração própria.

Outro aspecto que foi observado no questionário do estudo de Henri e Journeault (2010), é que ele adotou a escala Likert de sete pontos. Porém, nas obras que lhe serviram de base para a elaboração do questionário, que neste estudo foram exploradas para fundamentar e elaborar o constructo da pesquisa e as variáveis de controle, constatou-se a utilização de uma escala de cinco pontos, que se optou 
também nesta pesquisa. Na escala, o escore 1 representa não usado em tudo, e no outro extremo, o escore 5 representa usa extensivamente.

\section{Hipóteses}

Como o eco-controle, de acordo com Henri e Journeault (2010), promove o comprometimento de cumprir metas pelos indivíduos, bem como a organização, coordenação e comunicação das prioridades estratégicas, acaba orientando os gestores das áreas críticas de preocupação, resultando em melhorias na alocação de recursos e no estabelecimento de prioridades com base em metas organizacionais. Desta forma, é possível estabelecer a primeira hipótese desta pesquisa:

$\mathrm{H}_{1}$ : $\mathrm{O}$ desempenho econômico está positivamente influenciado pelo eco-controle.

Espera-se uma relação positiva, pelo fato do eco-controle fornecer informações ambientais não divulgadas nas demonstrações contábeis e contribuir para vantagens competitivas e desenvolvimento de capacidades organizacionais para desempenho superior.

Investimentos ambientais podem acarretar certos custos de implantação no curto prazo e resultar em benefícios com incentivos simples, como redução de resíduos, conservação de energia, reutilização de materiais. Além disso, o desempenho ambiental superior poderá fornecer vantagens competitivas e oportunidades de aumentar as receitas, cumprindo as necessidades de consumidores (Hart, 1995). Assim, formula-se a seguinte hipótese:

$\mathrm{H}_{2 \mathrm{a}}: \mathrm{O}$ desempenho ambiental é positivamente influenciado pelo eco-controle.

É esperada uma relação positiva, em decorrência das empresas a cada dia que passa darem maior importância aos aspectos ambientais e à sustentabilidade, preocupando-se com a natureza e com a renovação de resíduos.

Para Russo e Fouts (1997), os recursos da empresa, e o desempenho organizacional serão reforçados por: I) ativos e tecnologia ambiental, II) desenvolvimento de capacidades de organização relacionadas com a gestão ambiental e III) recursos intangíveis, como liderança em assuntos ambientais e capacidade de influenciar as políticas públicas. 
Ressalta que maior desempenho ambiental oportuniza melhorar as relações públicas e imagem corporativa, bem como receber legitimidade social, que pode contribuir para o desempenho econômico (Patten, 2005). Estabelece-se assim a seguinte hipótese:

$\mathrm{H}_{2 \mathrm{~b}}$ : $\mathrm{O}$ desempenho econômico é influenciado positivamente pelo eco-controle por meio do desempenho ambiental.

Da mesma forma que nas hipóteses $\mathrm{H}_{1}$ e a $\mathrm{H}_{2 \mathrm{a}}$ espera-se uma relação positiva, pelas vantagens competitivas e melhoria de capacidades organizacionais, por meio de melhorias em aspectos ambientais, cada vez mais comuns em empresas ambientalmente responsáveis.

\section{Variáveis de controle}

Ao considerar a potencial influência de outros fatores sobre as relações entre ecocontrole, desempenho ambiental e desempenho econômico, cinco variáveis de controle, baseadas nos estudos de Henri e Journeault (2010), foram examinadas: exposição ambiental, visibilidade pública, preocupação ambiental, pressões das partes interessadas e tamanho.

Exposição ambiental: Para Al-Tuwaijri et al. (2004), empresas que enfrentam maiores exposições ambientais podem apresentar maiores incentivos para um bom desempenho ambiental, ao considerar os custos potenciais futuros. Esta variável de controle é representada no estudo por empresas que apresentam o Índice de Sustentabilidade Empresarial (ISE), que são empresas socialmente responsáveis, sustentáveis e rentáveis para aplicar seus recursos. Para estas empresas da amostra, estabeleceu-se uma variável dicotômica 1 (um), e para as não listadas no período deste estudo 0 (zero).

Com a preocupação dos investidores de encontrar empresas socialmente responsáveis, considerando que as sustentáveis geram valor para o acionista no longo prazo, por estarem mais preparadas para enfrentar riscos econômicos, sociais e ambientais, foi estabelecido o Índice de Sustentabilidade Empresarial (ISE). Um selo de qualidade ou índice de ações para os investimentos socialmente responsáveis, representado por empresas preparadas para enfrentar riscos econômicos, sociais e ambientais, presidido por um Conselho Deliberativo da BM\&FBOVESPA. Para 
as empresas pré-selecionadas, com as 200 ações mais líquidas, é encaminhado um questionário, e o conselho escolhe as com melhor classificação, considerando o relacionamento com empregados, fornecedores e comunidade, governança corporativa e impacto ambiental de suas atividades. Este índice classifica e reconhece as empresas preocupadas com o impacto ambiental das suas atividades (BM\&FBOVESPA).

Visibilidade pública: Para Al-Tuwaijri et al. (2004) é a exposição da empresa ao escrutínio público. Empresas que são caracterizadas por esse fato, podem ser mais propensas a incorrer em custos políticos associados ao desempenho ambiental e econômico. Na variável propriedade, considerou-se o enfoque de que empresas privadas estão associadas a baixa visibilidade pública, e empresas públicas a alta visibilidade. Estabeleceu-se para as empresas públicas uma variável dicotômica 1 (um), e para as privadas 0 (zero).

Preocupação ambiental: De acordo com Al-Tuwaijri et al. (2004), refere-se à importância atribuída pela empresa para integração das questões ambientais dentro das práticas organizacionais. Quando a escolha para integrar as questões ambientais dentro das práticas organizacionais é completamente voluntária, ela reflete um forte compromisso da administração para a melhoria do meio ambiente e, consequentemente, do desempenho econômico. A preocupação ambiental é representada por um instrumento de quatro itens, desenvolvidos por Judge e Douglas (1998), em que índices mais altos sugerem maior integração das questões ambientais no processo de planejamento estratégico. Verificou-se, em que medida a organização utiliza as opções entre os itens: I) cobertura funcional; II) integração das questões ambientais; III) desempenho financeiro; IV) desempenho ambiental.

Pressões das partes interessadas: São as manifestações de interesse e influência de grupos ou indivíduos (Henriques e Sadorsky, 1999). De acordo com Alberton e Costa Jr (2007) as "pressões ambientais podem ser impostas às empresas por acionistas, investidores, empregados, fornecedores, consumidores, concorrentes, órgãos governamentais de controle ambiental, ONGs e por outros". Com pressão das partes interessadas, ocorrem maiores incentivos para um bom desempenho ambiental, uma forma de persuadir os investimentos e operações da empresa (Al-Tuwaijri et al., 2004). Para pressões das partes interessadas empregou-se o instrumento de Buysse e Verbeke (2003), em que escores mais alto indicam maior pressão de vários interessados, destacando-se pressões das: I) partes interessadas 
externas; II) partes interessadas secundárias; III) partes interessadas internas; IV) interessados reguladoras.

Tamanho: Henri e Journeault (2010) ressaltam a importância relativa das atividades ambientais em empresas maiores, ao proporcionar redução de custos ou maiores potenciais em receitas relacionadas a questões ambientais. Desta maneira, o tamanho da empresa também pode ser classificado como uma das variáveis de controle. A utilização da variável tamanho foi medida pelo logaritmo neperiano do número de empregados.

Nestes contextos, a influência direta e indireta de eco-controle sobre o desempenho econômico pode ser maior, se forem considerados a importância das atividades e os temas ambientais. Desse modo, estabeleceram mais duas hipóteses:

$\mathrm{H}_{3}$ : O efeito direto do eco-controle sobre o desempenho econômico é maior para as empresas com a) maior exposição ambiental, b) maior visibilidade pública, c), maior preocupação ambiental, d) maior pressão por parte dos interessados e e) maior tamanho.

$\mathrm{H}_{4}$ : $\mathrm{O}$ efeito indireto do eco-controle sobre o desempenho econômico por meio do desempenho ambiental é maior para as empresas com a) maior exposição ambiental, b) maior visibilidade pública, c) maior preocupação ambiental, d) maior pressão por parte dos interessados e e) maior tamanho.

Espera-se que haja tanto um efeito direto do eco-controle sobre o desempenho econômico, quanto um efeito indireto do eco-controle por meio do desempenho ambiental sobre o desempenho econômico, de maneira positiva, nas empresas, em virtude das influências das variáveis de controle.

\section{Procedimentos de análise dos dados}

No procedimento de análise dos resultados não se utilizaram a análise fatorial confirmatória, equações estruturais e o teste de Sobel, que foram aplicados no estudo de Henri e Journeault (2010), já que não conseguiram comprovar uma influência positiva e direta do eco-controle no desempenho econômico, nem sobre as influências de fatores de desempenho ambiental. 
Neste estudo adotou-se a análise por correlação canônica, que de acordo com Hair et al. (2005) "pode utilizar-se tanto em dados numéricos quanto não-numéricos para variáveis dependentes ou independentes", expressa na seguinte equação:

$$
\begin{gathered}
\mathrm{Y}_{1}+\mathrm{Y}_{2}+\mathrm{Y}_{3}+\ldots+\mathrm{Y}_{n}= \\
\begin{array}{c}
\mathrm{X}_{1}+\mathrm{X}_{2}+\mathrm{X}_{3}+\ldots+\mathrm{X}_{n} \\
\text { (métricas, não-numéricas) }
\end{array}
\end{gathered}
$$

Onde:

$Y=$ Variáveis dependentes, ou criterion

$X=$ Variáveis independentes, ou predictor.

A análise de correlação canônica, de acordo com Hair et al. (2005), identifica uma estrutura ótima de cada conjunto de variáveis, em que maximiza a relação entre o conjunto de variáveis, sejam elas independentes ou dependentes, sendo possível adequar qualquer variável métrica sem a presunção rigorosa de efetuar o cálculo de normalidade. Os autores definem a análise de correlação canônica como "um modelo estatístico multivariado que facilita o estudo de inter-relações entre conjuntos de múltiplas variáveis dependentes e múltiplas variáveis independentes [...], simultaneamente prevê múltiplas variáveis dependentes a partir de múltiplas variáveis independentes".

Fávero et al. (2009) explicam que "o objetivo da correlação canônica é quantificar a força da relação existente entre dois vetores de variáveis, representados pelas dependentes e independentes". Os autores explicam que a análise de correlação canônica e a análise fatorial são similares, a diferença é que na análise fatorial o primeiro vetor comporta o máximo de variância presente nos dados, e na correlação canônica, o novo vetor é identificado para cada vetor de variável de tal modo, que a correlação que ocorre entre ele é máxima, conforme.

Hair et al. (2005, p. 375) apresentam evidencias que permitem inferir que com a correlação canônica a verificação das variáveis se concretizará em uma relação benéfica. Afirmam que a análise canônica permite "combinar na forma de uma medida composta o que de outra maneira poderia ser um grande número intratável de correlações bivariadas entre conjuntos de variáveis". Destacam que ela "é útil para identificar relações gerais entre múltiplas variáveis independentes e dependentes, particularmente, quando o pesquisador tem pouco conhecimento a priori sobre as relações entre os conjuntos de variáveis". 


\section{Descrição e análise dos resultados}

Para medir a confiabilidade de cada item do constructo, conferiu-se o Alfa de Cronbach. Para este estudo constatou significância acima de 0,8901 para todos os constructos.

E para chegar aos resultados deste estudo, efetuou-se a análise de correlação canônica, que para Hair et al. (2005) é quantificar a força da relação, entre os dois conjuntos de variáveis independentes e dependentes, e identificar a dimensão entre estas variáveis, além de maximizar a relação entre estas dimensões. Desta forma, foi possível estabelecer a relação explicitada na quadro 4.

\section{Quadro 4}

\section{Resultado da relação por meio da correlação canônica}

\begin{tabular}{ll|l|l}
\hline \multicolumn{2}{c|}{ Descrição do caminho } & Correlação Canônica \\
\hline Eco-controle & & Desempenho econômico & $0.6187 * * *$ \\
\hline Eco-controle & \multicolumn{2}{l|l}{} \\
\hline Desempenho ambiental & Desempenho ambiental & $0.7953 * * *$ \\
\hline Outras práticas de gestão ambiental & Desempenho econômico & $0.6462 * * *$ \\
\hline
\end{tabular}

$* * * \mathrm{p}<0,001$

Fonte: Dados da pesquisa.

Na correlação em que se busca analisar a influência do eco-controle no desempenho econômico e que testa a hipótese $\mathrm{H}_{1}$ deste estudo, ocorreu uma relação positiva conforme previsto. É possível inferir que as combinações entre os conjuntos de variáveis apresentam uma alta correlação, indo ao encontro dos estudos de Bennett e James (1998) e Sharma (2000), porém de encontro ao resultado do estudo de Henri e Journeault (2010).

Quando verificados os caminhos, o desempenho ambiental é influenciado pelo eco-controle, que corresponde à hipótese $\mathrm{H}_{2 \mathrm{a}}$. Este resultado coaduna com Hart (1995) e Sharma e Vredenburg (1998), que esta relação é positiva e permite confirmar que os investimentos ambientais podem resultar em benefícios com incentivos simples, como redução de resíduos, conservação de energia, reutilização de materiais, além de fornecer vantagens competitivas e oportunidades de aumentar as receitas. 
$\mathrm{O}$ caminho seguinte, que comprova a hipótese $\mathrm{H}_{2 \mathrm{~b}}$, mostra que o desempenho econômico é influenciado pelo eco-controle por meio do desempenho ambiental. Embora esta hipótese tenha sido estabelecida no estudo de Henri e Journeault (2010), nos resultados de sua pesquisa não constataram relevância, diferente dos achados desta pesquisa.

Neste estudo também foram analisadas as influências do desempenho ambiental por meio de outras práticas de gestão ambiental, conforme recomendado por Aragão-Correa (1998), confirmando a importância dedicada às práticas ambientais pelas entidades.

Em uma análise posterior verificou-se se o eco-controle estabelece influências no desempenho econômico das empresas, por meio de efeitos diretos e indiretos. Corrobora-se assim o preconizado por Hair et al. (2005, p. 375), que dos "resultados obtidos de uma análise canônica devem surgir respostas a questões referentes ao número de maneiras nas quais os dois conjuntos de variáveis múltiplas estão relacionados, às forças das relações e à natureza das relações definidas". Neste contexto analisaram-se as variáveis de controle, conforme a quadro 5, em que se apresentam os efeitos separados por variável pesquisada.

\section{Quadro 5}

Resultado das influências diretas e indiretas das variáveis de controle para com o eco-controle

\begin{tabular}{l|c|c|c|c|c}
\hline \multicolumn{1}{c|}{ Descrição do caminho } & $\begin{array}{c}\text { Exposição } \\
\text { ambiental }\end{array}$ & $\begin{array}{c}\text { Visibilidade } \\
\text { Pública }\end{array}$ & $\begin{array}{c}\text { Preocupação } \\
\text { ambiental }\end{array}$ & $\begin{array}{c}\text { Partes } \\
\text { interessadas }\end{array}$ & Tamanho \\
\hline $\begin{array}{l}\text { Eco-controle - Desempenho } \\
\text { econômico }\end{array}$ & $0.6189^{* * *}$ & $0.6436^{* * *}$ & $0.7592^{* * *}$ & $0.7001^{* * *}$ & $0.6224 * * *$ \\
\hline $\begin{array}{l}\text { Eco-controle - Desempenho } \\
\text { ambiental }\end{array}$ & $0.7953^{* * *}$ & $0.7958^{* * *}$ & $0.9120^{* * *}$ & $0.8675^{* * *}$ & $0.8064 * * *$ \\
\hline $\begin{array}{l}\text { Desempenho ambiental } \\
\text { - Desempenho econômico }\end{array}$ & $0.6576^{* * *}$ & $0.6557 * * *$ & $0.7878^{* * *}$ & $0.6840^{* * *}$ & $0.6587 * * *$ \\
\hline $\begin{array}{l}\text { Outras práticas de gestão } \\
\text { ambiental - Desempenho } \\
\text { ambiental }\end{array}$ & $0.8650^{* * *}$ & $0.8648^{* * *}$ & $0.9572^{* * *}$ & $0.9311^{* * *}$ & $0.8775^{* * * *}$ \\
\hline
\end{tabular}

$* * * \mathrm{p}<0,001$

Fonte: Dados da pesquisa.

Depreende-se da quadro 5, que existem fortes influências para cada variável de controle. Observa-se isso na relação do eco-controle com o desempenho econômico, como também do eco-controle por meio do desempenho ambiental, desempenho 
ambiental com o desempenho econômico, e da mesma forma para com outras práticas de gestão ambiental. Deste modo, é possível confirmar as hipóteses $\mathrm{H}_{3}$ e $\mathrm{H}_{4}$.

Entre as variáveis de controle consideradas, aquela com maior destaque é a da preocupação ambiental. Portanto, comprovam-se as evidencias de Judge e Douglas (1998), que a importância conferida pelas empresas às questões ambientais dentro das práticas organizacionais se refletem em um forte compromisso da administração para a melhoria do meio ambiente e, por conseguinte, do desempenho econômico.

\section{Conclusão}

O estudo objetivou verificar a influência do eco-controle no desempenho ambiental e econômico de empresas. Pesquisa descritiva foi realizada por meio de levantamento e abordagem quantitativa do problema. Um questionário, adaptado do estudo de Henri e Journeault (2010), foi enviado aos diretores das empresas listadas na BM\&FBOVESPA e com seus dados na Economática ${ }^{\circledR}$, com exceção das entidades financeiras, sendo a amostra composta das 106 empresas respondentes. $\mathrm{Na}$ análise dos dados replicaram-se os procedimentos do estudo de base, distinguindo-se pela aplicação de correlações canônicas.

No estudo de Henri e Journeault (2010), os resultados alcançados não foram satisfatórios, uma vez que o eco-controle não apresentou influência direta no desempenho econômico. Somente constataram uma influência indireta, por meio das variáveis de controle relativas ao contexto de exposição ambiental, visibilidade pública, preocupação ambiental, pressão das partes interessadas e tamanho das empresas. Ressalta-se que para a análise dos dados os autores utilizaram equações estruturais e o teste de Sobel.

$\mathrm{Na}$ tentativa de verificar se no contexto brasileiro estas evidências buscadas no estudo de Henri e Journeault (2010) se confirmam, procedimentos metodológicos idênticos foram utilizados, com exceção do tratamento estatístico aplicado aos dados, em que se utilizou a correlação canônica, na tentativa de encontrar correlações positivas significantes, o que se confirmou com resultados positivos.

Resultados divergentes entre ambas as pesquisas podem decorrer das adaptações no instrumento da pesquisa, do ambiente diverso em que foram realizadas e do tratamento estatístico aplicado. Este estudo ocorreu no contexto brasileiro, em com- 
panhias abertas, que gradualmente vem se preocupando e valorizando aspectos ambientais, de eco-controle e sustentabilidade. Nas correlações canônicas foi identificada cada relação das variáveis latentes do constructo, uma a uma, verificando sua verdadeira relação e essência para as respostas da influencia do eco-controle no desempenho ambiental e econômico das empresas. Esta técnica objetiva maximizar a correlação entre as composições lineares das variáveis Y e X (Fávero et $a l ., 2009)$, portanto é uma forma mais robusta de verificação em comparação às equações estruturais, que faz esse mesmo procedimento em um único cálculo.

De modo geral, para cada caminho efetuado com base na correlação canônica resultou evidente uma relação entre as variáveis independentes e dependentes. Todos os $P$ value foram inferiores a 0,001 , e os conjuntos de correlações apresentam-se estatisticamente significantes no nível maior que 95,0\%. Assim é possível estabelecer que o eco-controle apresenta correlação positiva e significativa com o desempenho econômico, tanto por meio de uma relação direta, como por intermédio das influências do desempenho ambiental. Desse modo, comprovam-se as seguintes hipóteses:

$\mathrm{H}_{1}$ : $\mathrm{O}$ desempenho econômico está positivamente influenciado pelo eco-controle. $\mathrm{H}_{2 \mathrm{a}}: \mathrm{O}$ desempenho ambiental é positivamente influenciado pelo eco-controle. $\mathrm{H}_{2 \mathrm{~b}}$ : O desempenho econômico é influenciado positivamente pelo eco-controle por meio do desempenho ambiental.

Com uma correlação canônica posterior, em que se relacionou cada variável estudada com cada variável de controle analisada, foi possível identificar uma correlação ainda maior, comprovando a relação direta e indireta do eco-controle com o desempenho econômico e do eco-controle com o desempenho econômico por meio do desempenho ambiental, para as empresas com maior exposição ambiental, maior visibilidade pública, maior preocupação ambiental, maior pressão por parte dos interessados e maior tamanho. O que comprova as seguintes hipóteses:

$\mathrm{H}_{3}$ : $\mathrm{O}$ efeito direto do eco-controle sobre o desempenho econômico é maior para as empresas com a) maior exposição ambiental, b) maior visibilidade pública, c), maior preocupação ambiental, d) maior pressão por parte dos interessados e e) maior tamanho.

$\mathrm{H}_{4}$ : $\mathrm{O}$ efeito indireto do eco-controle sobre o desempenho econômico por meio do desempenho ambiental é maior para as empresas com a) maior exposição am- 
biental, b) maior visibilidade pública, c) maior preocupação ambiental, d) maior pressão por parte dos interessados e e) maior tamanho.

Assim, conclui-se que nas empresas pesquisadas o eco-controle influenciou o desempenho econômico e ambiental. Os achados diferem do estudo de Henri e Journeault (2010), que não constataram efeito direto do eco-controle sobre o desempenho econômico, apenas influência indireta nas variáveis de controle. Estas observações fomentam a literatura com insights sobre a contribuição da contabilidade gerencial ao desenvolvimento sustentável.

Para novos estudos sobre o tema investigado, recomenda-se analisar este efeito com aplicação de outros métodos estatísticos, como por exemplo, análise por caminhos ou pela abordagem das equações estruturais, como abordado por Henri e Journeault (2010). Procedimentos estatísticos distintos podem comprovar ou não a influência do eco-controle no desempenho econômico dessas empresas.

\section{Referências}

Alberton, A. e N.C.A. Costa Jr. (2007). Meio ambiente e desempenho econômicofinanceiro: benefícios dos Sistemas de Gestão Ambiental (SGAs) e o impacto da ISO 14001 nas empresas brasileiras. RAC Eletrônica (1): 153-171.

Al-Tuwaijri, S.A., T.E. Christensen e K.E. Hughes (2004). The relations among environmental disclosure, environmental performance, and economic performance: a simultaneous equations approach. Accounting, Organizations and Society (29): 447-471.

Aragón-Correa, J.A. (1998). Strategic proactivity and firm approach to the natural environment. The Academy of Management Journal 41 (5): 556-567.

Baines, A. e K. Langfield-Smith (2003). Antecedents to management accounting change: a structural equation approach. Accounting, Organizations and Society 28 (7/8): 675-698.

Barata, M.M.L., D.C. Kligerman e C. Minayo-Gómez (2007). A gestão ambiental no setor público: uma questão de relevância social e econômica. Ciênc. Saúde Coletiva 12 (1): 165-170. 
Bebbington, J., R. Gray, I. Thomson e D. Walters (1994). Accountant's attitudes and environmentally-sensitive accounting. Accounting and Business Research 24 (94): 109-120.

Bennett, M. e P. James (1998). Environment under the spotlight: current practice and future trends in environment - Related performance measurement for business. London: Association of Chartered Certified Accountants. Disponível em: http://search.proquest.com/docview/195659067/fulltextPDF/ 1344C63E9476C7CC6D5/2?accountid=14643

Bolsa de Valores, Mercadorias e Futuros (BM\&FBOVESPA). Índice de Sustentabilidade Empresarial (ISE). Disponível em: http://www.bmfbovespa.com. br/Indices/download/ISE.pdf

Burritt, R.L. (2004). Environmental management accounting: roadblocks on the way to the green and pleasant land. Business Strategy and the Environment 13 (1): 13-32.

Burritt, R. e S. Schaltegger (2001). Eco-efficiency in corporate budgeting. Environmental Management and Health 12 (2/3): 158.

Buysse, K. e A. Verbeke (2003). Proactive environmental strategies: a stakeholder management perspective. Strategic Management Journal 24 (5): 453-470.

Chenhall, R.H. (2005). Integrative strategic performance measurement systems, strategic alignment of manufacturing, learning and strategic outcomes: an exploratory study. Accounting, Organizations and Society 30 (5): 395-422.

Dixon, R., G.A. Mousa e A. Woodhead (2005). The role of environmental initiatives in encouraging companies to engage in environmental reporting. European Management Journal 23 (6): 702-716.

Eckel, L., K. Fisher e G. Russell (1992). Environmental performance measurement. CMA Management 66 (2): 16.

Fávero, L. P., P. Belfiore, F. L. Silva e B. L. Chan (2009). Análise de dados: modelagem multivariada para tomada de decisões. Rio de Janeiro: Elsevier, Campus. 
Figge, F., T. Hahn, S. Schaltegger e M. Wagner (2002). The sustainability balanced scorecard: linking sustainability management to business strategy. Business Strategy and the Environment 11: 269-284.

Hair, J.F., R.E. Anderson, R.L. Tatham e W.C. Black (2005). Análise multivariada de dados. 5 ed. Porto Alegre: Bookman.

Hart, S.L. (1995). A natural-resource-based view of the firm. Academy of Management Review 20 (4): 986-1014.

Henri, J.F. e M. Journeault (2010). Eco-control: the influence of management control systems on environmental and economic performance. Accounting, Organizations and Society (35): 63-80.

Henriques, I. e P. Sadorsky (1999). The relationship between environmental commitment and managerial perceptions of stakeholder importance. Academy of Management Journal 42 (1): 87.

Ilinitch, A.Y., N.S. Soderstrom e T.E. Thomas (1998). Measuring corporate environmental performance. Journal of Accounting and Public Policy 17: 383408.

Judge, W.Q. e T.J. Douglas (1998). Performance implications of incorporating natural environmental issues into the strategic planning process: an empirical assessment. The Journal of Management Studies 35 (2): 241-262.

Kerlinger, F.N. (1980). Metodologia da pesquisa em ciências sociais: um tratamento conceitual. São Paulo: EPU/EDUSP.

Muller, K., e A. Wittke (1997). The Ciba case: the financial quantification of environmental strategies with Value-Based Environmental Management. In S. Schaltegger e A. Sturm (eds.). Eco-Efficiency by Eco-Controlling. Zúrich: VDF. Disponível em: http://www.ellipson.com/files/ebooks/EC.pdf

Mobus, J.L. (2005). Mandatory environmental disclosures in a legitimacy theory context. Accounting, Auditing and Accountability Journal 18 (4): 492-517. 
Patten, D.M. (2005). The accuracy of financial report projections of future environmental capital expenditures: A research note. Accounting, Organizations and Society (30): 457-468.

Richardson, R.J. e J.A.S. Peres (1989). Pesquisa social: metodos e tecnicas. 2. ed. Sao Paulo: Atlas.

Russo, M.V. e P.A. Fouts (1997). A resource-based perspective on corporate environmental performance and profitability. Academy of Management Journal 40 (3): 534-559.

Said, A.A., H.R.H. Elnaby e B. Wier (2003). An empirical investigation of the performance consequences of nonfinancial measures. Journal of Management Accounting Research (15): 193-223.

Schaltegger, S. e R. Burritt (2000). Contemporary environmental accounting. Sheffiekd: Greenleaf Publishing.

Sharma, S. (2000). Managerial interpretations and organizational context as predictors of corporate choice of environmental strategy. Academy of Management Journal (43): 681-697.

e H. Vredenburg. (1998). Proactive corporate environmental strategy and the development of competitively valuable organizational capabilities. Strategic Management Journal 19 (8): 729-753.

Shrivastava, P. (1995). The role of corporations in achieving ecological sustainability. Academy of Management Review 20 (4): 936-960. 
